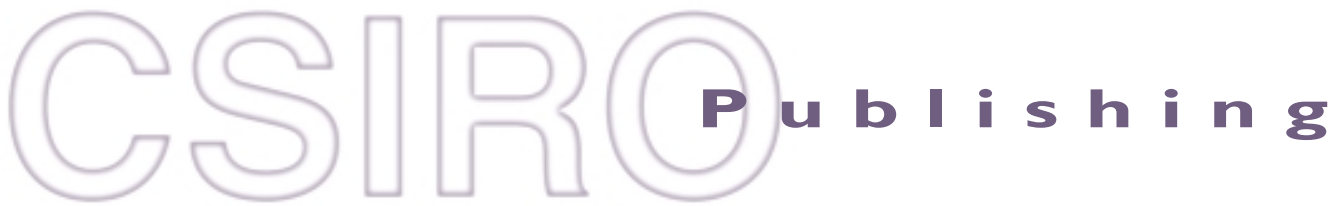

\section{Australian Journal of Experimental Agriculture}

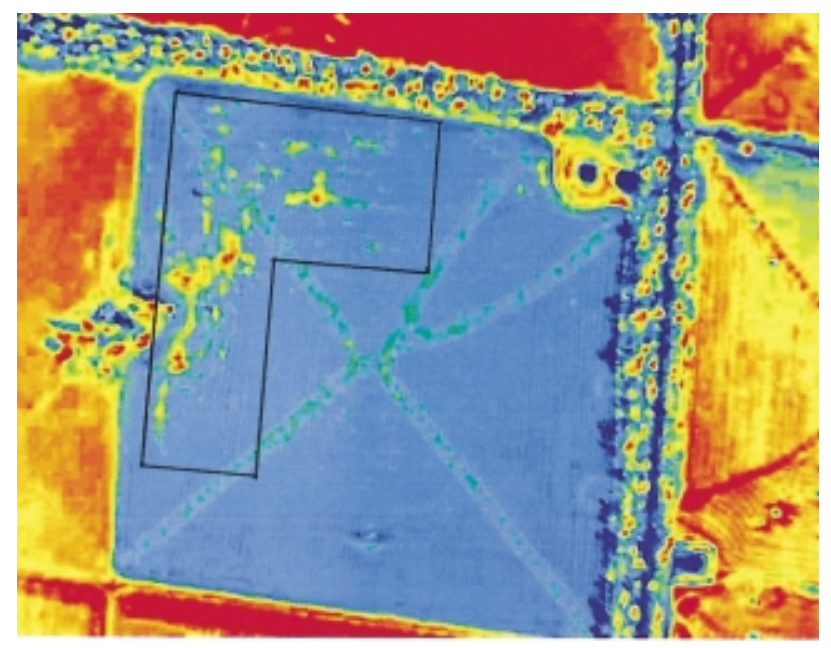

Volume 41, 2001

(C) CSIRO 2001

... a journal publishing papers at the cutting edge of applied agricultural research

All enquiries and manuscripts should be directed to:

Australian Journal of Experimental Agriculture

CSIRO Publishing

PO Box 1139 (150 Oxford Street)

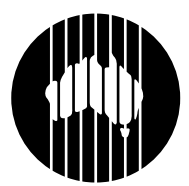

Collingwood, Vic. 3066, Australia

Telephone: +6139662 7614

Fax: +6139662 7611

CSIRO

Email: ajea@publish.csiro.au

Published by CSIRO Publishing for the Standing Committee on

Agriculture and Resource Management (SCARM)

www.publish.csiro.au/journals/ajea 


\title{
Saprophytic microorganisms with potential for biological control of Botrytis cinerea on Geraldton waxflower flowers
}

\author{
D. R. Beasley ${ }^{\mathrm{AD}}$, D. C. Joyce ${ }^{\mathrm{BE}}$, L. M. Coates ${ }^{\mathrm{C}}$ and A. H. Wearing ${ }^{\mathrm{A}}$

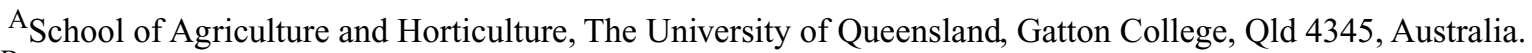 \\ ${ }^{B}$ Postharvest Technology Laboratory, Cranfield University, Silsoe, Bedfordshire MK45 4DT, United Kingdom. \\ ${ }^{\mathrm{C}}$ Queensland Horticulture Institute, Department of Primary Industries, 80 Meiers Road, \\ Indooroopilly, Qld 4068, Australia. \\ DPresent address: Queensland Horticulture Institute, Department of Primary Industries, 80 Meiers Road, \\ Indooroopilly, Qld 4068, Australia. \\ EAuthor for correspondence; e-mail: d.joyce@cranfield.ac.uk
}

\begin{abstract}
Saprophytic bacteria, yeasts and filamentous fungi were isolated from Geraldton waxflower flowers and screened to identify potential antagonism towards Botrytis cinerea. Isolates from other sources (e.g. avocado) were also tested. Isolates were initially screened in vitro for inhibition of $B$. cinerea conidial germination, germ tube elongation and mycelial growth. The most antagonistic bacteria, yeasts and fungi were selected for further testing on detached waxflower flowers. Conidia of the pathogen were mixed with conidia or cells of the selected antagonists, co-inoculated onto waxflower flowers, and the flowers were sealed in glass jars and incubated at $20^{\circ} \mathrm{C}$. The number of days required for the pathogen to cause flower abscission was determined. The most antagonistic bacterial isolate, Pseudomonas sp. 677, significantly reduced conidial germination and retarded germ tube elongation of $B$. cinerea. None of the yeast or fungal isolates tested was found to significantly reduce conidial germination or retard germ tube elongation, but several significantly inhibited growth of B. cinerea. Fusarium sp., Epicoccum sp. and Trichoderma spp. were the most antagonistic of these isolates. Of the isolates tested on waxflower, Pseudomonas sp. 677 was highly antagonistic towards $B$. cinerea and delayed waxflower abscission by about 3 days. Trichoderma harzianum also significantly delayed flower abscission. However, as with most of the fungal antagonists used, inoculation of waxflower flowers with this isolate resulted in unsightly mycelial growth.
\end{abstract}

\section{Introduction}

Geraldton waxflower (Chamelaucium uncinatum Schauer) is one of Australia's most economically important cut flower exports (Seaton et al. 1993) and is increasingly important in the international cut flower industry (Joyce 1988). It is grown extensively in Australia and accounts for about $50 \%$ of the value of native flower exports (Joyce and Wearing 1996).

Postharvest bud and flower abscission is one of the major problems experienced during transport, handling and marketing of waxflower (Joyce 1993). Abscission is often caused by wound-induced endogenous ethylene production brought about by infection of flower tissues by fungal pathogens (Joyce 1993). Botrytis cinerea Pers.:Fr. has been implicated as the primary fungal pathogen responsible for wound-induced endogenous ethylene production (Tomas et al. 1995).

Present chemical control measures are somewhat inefficient, since many or all floral stages from the shiny bud through to pink hypanthium may be present on the same plant at any one time (Olley et al. 1996). Accordingly, developing buds may not receive adequate protection against subsequent challenge by fungal pathogens, unlike open flowers where exposed reproductive structures are more likely to receive fungicidal treatment. In addition, the development of fungicide resistance has resulted in the exacerbation of many diseases. Strains of $B$. cinerea that are resistant to benomyl have been isolated from waxflower (Taylor et al. 1996). Moreover, there is significant public unease over the use of pesticides and their effect on the environment, which has led to consumer resistance (El-Ghaouth et al. 1992; Prusky and Keen 1993).

Biological control offers an alternative to chemical control. Bacterial, yeast and fungal antagonists can provide excellent control of $B$. cinerea. Success has been reported for a range of crops including grapes and strawberries (Elad 1994; Sutton 1995). Pseudomonas sp., Aureobasidium pullulans (de Bary) G. Arnaud and Gliocladium roseum Bainier are examples of antagonistic microorganisms that can inhibit germination and growth of $B$. cinerea (Janisiewicz and Roitman 1988; Elad et al. 1994; Sutton et al. 1997).

Saprophytic microorganisms can inhibit $B$. cinerea through various mechanisms. They may, for example, 
compete aggressively for space and nutrients (Blakeman 1993). Carbohydrates, amino and organic acids, mineral elements and leaf waxes found on the aerial surfaces of plants provide nutrition for saprophytes (Blakeman and Atkinson 1981). Augmentation of saprophyte populations depletes available exogenous nutrients and, thereby, inhibits germination and subsequent growth and development of pathogens, such as B. cinerea (Brodie and Blakeman 1975). Other mechanisms of biological control include direct parasitism, production of antibiotics and/or the induction of host plant resistance (Sutton et al. 1997).

Performance of microbial antagonists in vitro can be poorly correlated with their performance in the field. Janisiewicz (1987) isolated $>800$ potential microbial antagonists from apple trees and screened them for antagonism towards the blue mould pathogen Penicillium expansum Link. While many of the isolates performed well in vitro, they did not inhibit decay on apple fruit. Nonetheless, in vitro studies involving inhibition of conidial germination and mycelial growth are still useful as a screening procedure for selection of potential antagonists.

Saprophytic microorganisms including bacteria, yeasts and filamentous fungi were isolated from the surface of waxflower flowers and screened for potential antagonism against $B$. cinerea. It was hypothesised that effective antagonists would inhibit pathogen-induced abscission of harvested waxflower flowers from their pedicels. Tests were conducted on harvested waxflowers (in planta) as well as in vitro. Inhibition of in vitro conidial germination and mycelial growth of $B$. cinerea by bacteria, yeasts and fungi were measured in addition to effects on flower abscission.

\section{Materials and methods}

Flower materials

Flowering waxflower cv. 'CWA Pink' stems were harvested at 0800 hours from plants growing on Ebonybrook farm near Gatton $\left(27^{\circ} 33^{\prime} \mathrm{S}, 152^{\circ} 17^{\prime} \mathrm{E}\right)$, south-east Queensland. They were transported about $1 \mathrm{~h}$ by road, standing upright in a container of distilled water, to the laboratory in Brisbane.

\section{Isolation of potential antagonists}

Flowers were cut from their stems, weighed in groups of 10 (about $1 \mathrm{~g}$ ) and washed in plastic bags containing $20 \mathrm{~mL}$ of phosphate buffered saline (PBS, $\mathrm{pH} 7.2$ ) and $0.02 \%(\mathrm{v} / \mathrm{v})$ Tween- 80 for $90 \mathrm{~s}$ using a Stomacher Lab-Blender 80 (Stirling, 1995). Washed samples were serially diluted in PBS to provide a 4 -fold dilution series. Ten replicates of 10 individual flowers per replicate were used.

Aliquots $(100 \mu \mathrm{L})$ of each dilution were placed in the centre of each separate $90 \mathrm{~mm}$ agar plate and spread using a sterile glass spreader. All cultures were incubated at $25^{\circ} \mathrm{C}$ in darkness.

Bacteria were grown on half-strength tryptic soy agar (half TSA; i.e. the normal concentration of tryptic soy broth was halved). The agar therefore consisted of $15 \mathrm{~g}$ tryptic soy broth, $18 \mathrm{~g}$ agar and $1 \mathrm{~L}$ distilled water. Cycloheximide $(75 \mathrm{mg} / \mathrm{mL})$ was added to the half TSA (593 $\mu \mathrm{g} / \mathrm{mL}$ agar) to inhibit fungal growth. Yeasts were grown on malt yeast extract agar (MYE). MYE consisted of $3 \mathrm{~g}$ yeast extract, $3 \mathrm{~g}$ malt extract, $5 \mathrm{~g}$ bacto peptone, $10 \mathrm{~g}$ D-glucose, $20 \mathrm{~g}$ agar and $1 \mathrm{~L}$ distilled water. The MYE medium was adjusted to $\mathrm{pH} 3.8$ by the addition of HCL to acidify the medium thereby inhibiting fungal growth.
Filamentous fungi were grown on half-strength streptomycin potato dextrose agar (half SPDA; i.e. the normal concentrations of potato extract and D-glucose were halved). Half PDA consisted of $2 \mathrm{~g}$ potato extract, $10 \mathrm{~g}$ D-glucose, $15 \mathrm{~g}$ agar and $1 \mathrm{~L}$ distilled water. Where appropriate, streptomycin sulfate $(10 \mathrm{mg} / \mathrm{mL})$ was added to the half SPDA $(50 \mu \mathrm{g} / \mathrm{mL}$ agar) to inhibit bacterial growth.

Isolates were subcultured within a week to obtain pure cultures of the various bacterial, yeast and fungal isolates. Single spore cultures of fungal isolates were obtained and then agar discs bearing the organisms were stored under sterile water. Fungal isolates from waxflower were identified to genus level, by observing conidia under the light microscope, according to the descriptions of Barnett (1960).

Besides microbes from waxflower flowers, the following microbial agents were evaluated against B. cinerea: Talaromyces sp. from Dr Lindy Coates, DPI, Brisbane; Trichoderma harzianum Rifai from Dr Andrew Rath, Abbott Laboratories, Sydney; Gliocladium roseum from Dr John Alcorn, DPI, Brisbane; and, Bacillus spp. (9 isolates), Enterobacter sp., Pseudomonas sp., Aureobasidum spp. (3 isolates), an Actinomycete, 2 white yeasts and 3 pink yeasts from Dr Marcelle Stirling, Biological Crop Protection, Brisbane.

\section{Effect on Botrytis cinerea conidial germination and growth}

Botrytis cinerea (BRIP 25227) and saprophytic fungal isolates were grown on half SPDA at $25^{\circ} \mathrm{C}$ under alternating $12 \mathrm{~h}$ near-UV light. Bacterial isolates were grown on half TSA at $25^{\circ} \mathrm{C}$ in darkness for 1-2 days before all experiments. Yeast isolates were grown on MYE at $25^{\circ} \mathrm{C}$ in darkness for 3-4 days before use. Conidia of B. cinerea and fungal isolates were obtained by washing 14-21-day-old colonies growing on half SPDA with sterile distilled water and dislodging the conidia with a sterile glass rod. The conidia were filtered through 2 layers of sterile gauze. The resultant conidial suspension was adjusted to a concentration of $5 \times 10^{5}$ conidia/mL using a haemocytometer. Bacteria and yeasts were removed from culture and placed in sterile distilled water using a sterile inoculating loop. The concentration of yeasts and bacteria was standardised to 0.8 absorbance unit at $600 \mathrm{~nm}$ using a Varian DMS 100S spectrophotometer.

The $B$. cinerea conidial suspension was mixed with the conidial or cell suspension of fungal, bacterial or yeast isolates in a ratio of $0.5 \mathrm{~mL}$ to $0.5 \mathrm{~mL}$. Aliquots $(100 \mu \mathrm{L})$ of the suspensions were placed on water agar in Petri dishes by means of a micropipette and spread evenly with a sterile glass rod. Conidial germination and germ tube length were determined after the dishes were incubated for $24 \mathrm{~h}$ at $25^{\circ} \mathrm{C}$ in darkness.

Germination percentage was determined by counting the number of germinated and non-germinated conidia in a field of view at $\times 100$ magnification (about 30 conidia). Two replicate Petri dishes and 5 samples (i.e. 5 fields of view) per Petri dish were used. Conidia were considered germinated when the germ tube was longer than the diameter of the conidia. Germ tube length was measured on 10 randomly selected B. cinerea conidia on each of 2 replicate Petri dishes.

To determine the effect of potential antagonists on mycelial growth of $B$. cinerea, a $5 \mathrm{~mm}$ diameter agar disc from a 7-day-old $B$. cinerea culture was placed at the centre of a $90 \mathrm{~mm}$ diameter Petri dish containing half PDA. Agar discs from saprophytic fungal cultures were placed onto the medium near opposite edges of the Petri dish, about $40 \mathrm{~mm}$ from the $B$. cinerea plug (Fig. 1). Bacteria and yeasts were spread over an area of $5 \mathrm{~mm}$ diameter on the agar with a sterile inoculating loop. Two replicate half PDA plates were used for each microorganism. Inhibition of fungal growth was assessed by measuring the inhibition zone $(\mathrm{mm})$ and colony diameter (mm) (Fig. 1) after incubation at $25^{\circ} \mathrm{C}$ for 7 days in darkness. By this time, $B$. cinerea in the control plates had reached the edge of the plate. Bacteria or yeast isolates that did not produce an inhibition zone but caused the fungus to grow sparsely were described as non-zonal competitors. 


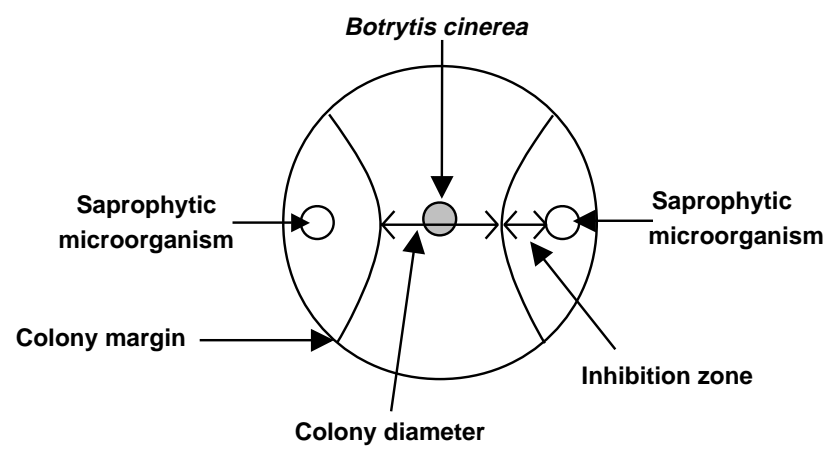

Figure 1. Relative position of Botrytis cinerea and potential microbial antagonists on half PDA plates used in mycelial growth inhibition tests.

\section{Effect on flower abscission}

Necrotic bracteoles clinging to fully open waxflower flowers were removed. Flowers with green, nectiferous hypanthiums were selected, detached from the stems, surface sterilised in $0.15 \% \mathrm{NaOCl}$ (sodium hypochlorite) for $60 \mathrm{~s}$, rinsed in sterile distilled water, and dried on blotting paper to remove surface moisture. Individual flowers were then placed in plastic stands within sterile $125 \mathrm{~mL}$ glass jars containing $10 \mathrm{~mL}$ sterile distilled water (Fig. 2). Each flower was inoculated with B. cinerea (BRIP 25227) alone or in combination with a fungal, yeast or bacterial antagonist.

The specific treatments were as follows: 1, control; 2, inoculation with $B$. cinerea; 3, Bacillus sp. 480; 4, Bacillus sp. 480 and B. cinerea; 5, Pseudomonas sp. 677; 6, Pseudomonas sp. 677 and B. cinerea; 7, control; 8, inoculation with B. cinerea; 9, Aureobasidium sp. 274; 10, Aureobasidium sp. 274 and B. cinerea; 11, Aureobasidium sp. 468; 12, Aureobasidium sp. 468 and B. cinerea; 13, control; 14, inoculation with $B$. cinerea; 15 , Epicoccum sp.; 16, Epicoccum sp. and B. cinerea; 17, Fusarium sp.; 18, Fusarium sp. and B. cinerea; 19, Trichoderma harzianum; and 20, Trichoderma harzianum and B. cinerea.

The $B$. cinerea conidial suspension was mixed with the conidial or cell suspension of the fungal, bacterial or yeast isolates in a ratio of $0.5 \mathrm{~mL}$ to $0.5 \mathrm{~mL}$. The resultant suspension was applied by placement of $2.5 \mu \mathrm{L}$ aliquots on the base of all 5 petals as well as onto the stigma (Fig. 2). The flowers were enclosed inside glass jars and incubated in the dark at $20^{\circ} \mathrm{C}$ for 14 days, or until the flowers abscised. Glass jars

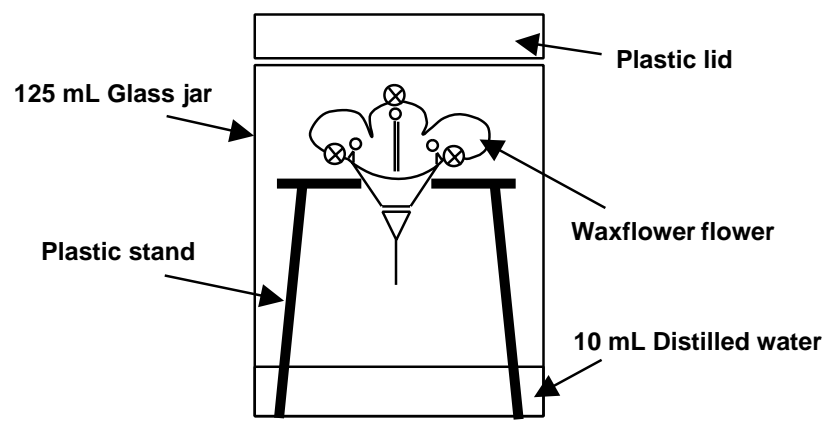

Figure 2. Diagrammatic representation of glass jars used to incubate Geraldton waxflowers after inoculation with Botrytis cinerea. The circles enclosing crosses mark the inoculation points. containing the waxflowers were dropped (impact energy $=0.245 \mathrm{~J}$ ) each day from a height of $20 \mathrm{~mm}$ to determine the number of days to flower abscission. Ten replicate flowers were used for each treatment.

Experimental design and statistical analyses

Effects of antagonistic bacteria, yeasts and fungi on conidial germination, germ tube elongation, mycelial inhibition and colony diameter of $B$. cinerea were evaluated using a 1-way ANOVA (Genstat 5 , Release 4.1). Treatment effects on the number of days to flower abscission were evaluated using a 2-way ANOVA (isolate $\times$ inoculation). Means were separated using the least significant difference test $(P=0.05)$.

\section{Results}

Isolates from waxflower flowers

Six different bacteria, 2 yeasts and 9 filamentous fungi were isolated from waxflower flowers. The majority of the bacterial isolates appeared similar in terms of culture characteristics to the Bacillus sp. isolates obtained from Dr Marcelle Stirling, Biological Crop Protection, Brisbane. One pink and 1 white yeast were isolated from waxflower, but neither was identified at genus level. A diverse range of filamentous fungi were isolated, these being Alternaria sp., Aspergillus sp., Cladosporium sp., Epicoccum sp., Fusarium sp., Nigrospora sp., Penicillium sp., Pestalotiopsis sp., Phoma sp. and Trichoderma sp.

\section{Effect of isolates on conidial germination and growth of Botrytis cinerea}

Overall, Pseudomonas sp. 677 was the most antagonistic bacterial isolate (Table 1) and significantly reduced conidial germination and germ tube elongation of $B$. cinerea. Bacillus sp. 480 and bacterial isolates 2 and 3 also reduced conidial germination. Bacterial isolates 2 and 3 significantly affected germ tube length, but Bacillus sp. 480 did not. Conversely, Bacillus sp. 75 significantly reduced germ tube length, but did not affect conidial germination. The most antagonistic bacteria in terms of mycelial inhibition were Bacillus spp., especially isolates 480 and 553 and bacterial isolate 2. These produced inhibition zones greater than $10 \mathrm{~mm}$. Neither Bacillus sp. 933 nor bacterial isolate 4 produced large inhibition zones. However, they both competed with $B$. cinerea by rapidly growing outwards from the edge of the agar plate (non-zonal inhibition). Neither of these isolates was overgrown by the pathogen, even when incubated for a further 2 weeks.

None of the yeasts tested significantly reduced either $B$. cinerea conidial germination or germ tube length (data not shown). The yeasts did not greatly inhibit $B$. cinerea mycelial growth. However, Aureobasidium sp. 140, 274 and 468 , as well as pink yeast 373 , all produced small inhibition zones and significantly reduced $B$. cinerea mycelial growth (Table 2).

Conidial germination and germ tube elongation were not significantly reduced by any of the fungal isolates tested (data not shown). Mycelial growth of $B$. cinerea was suppressed substantially by Fusarium sp. and Nigrospora sp. 
Table 1. Relative ability of bacterial isolates to inhibit Botrytis cinerea conidial germination and germ tube elongation after incubation for $24 \mathrm{~h}$ at $25^{\circ} \mathrm{C}$ on water agar and mycelial growth after incubation for 7 days at $25^{\circ} \mathrm{C}$ on half-strength potato dextrose agar

Total number of observations for germination percentage was 10 ( 2 replications $\times 5$ samples $)$ and germ tube length was 20 ( 2 replications $\times 10$ samples)

Means within each column followed by the same letter are not significantly different at $P=0.05$ Actinomycete 202, Bacillus spp., Enterobacter sp., and Pseudomonas sp. were obtained from Dr Marcelle Stirling, Biological Crop Protection; all other bacteria were isolated from waxflower Significance: germination $\%, P=0.018$; germ tube length, $P=0.003$; inhibition zone, $P<0.001$; colony diameter, $P<0.001$

\begin{tabular}{|c|c|c|c|c|}
\hline Isolate & $\begin{array}{c}\text { Germination } \\
(\%)\end{array}$ & $\begin{array}{l}\text { Germ tube } \\
\text { length }(\mu \mathrm{m})\end{array}$ & $\begin{array}{l}\text { Inhibition } \\
\text { zone }(\mathrm{mm})\end{array}$ & $\begin{array}{c}\text { Colony } \\
\text { diameter }(\mathrm{mm})\end{array}$ \\
\hline No. of replicates $(n)$ & 2 & 2 & 2 & 2 \\
\hline Control & 96.4ab & $184.0 \mathrm{a}$ & $0 \mathrm{~h}$ & $90.0 \mathrm{a}$ \\
\hline Actinomycete 202 & $98.4 \mathrm{a}$ & $159.0 \mathrm{ab}$ & $6.5 \mathrm{de}$ & $51.0 \mathrm{~cd}$ \\
\hline Bacillus sp. 75 & $96.2 \mathrm{ab}$ & $105.0 \mathrm{bcd}$ & 4.0efg & $60.5 b$ \\
\hline Bacillus sp. 78 & $91.2 \mathrm{abc}$ & $127.0 \mathrm{abc}$ & $0.0 \mathrm{~h}$ & $90.0 \mathrm{a}$ \\
\hline Bacillus sp. 301 & $91.9 \mathrm{abc}$ & $128.5 \mathrm{ab}$ & $6.0 \mathrm{def}$ & $48.5 \mathrm{cde}$ \\
\hline Bacillus sp. 359 & 85.0abcde & $140.0 \mathrm{ab}$ & $\mathrm{Oh}$ & $90.0 \mathrm{a}$ \\
\hline Bacillus sp. 480 & $73.0 \mathrm{de}$ & $129.5 \mathrm{ab}$ & $16.8 \mathrm{a}$ & $28.0 \mathrm{~g}$ \\
\hline Bacillus sp. 544 & $89.4 \mathrm{abc}$ & $141.0 \mathrm{ab}$ & $7.0 \mathrm{~d}$ & $43.5 \mathrm{ef}$ \\
\hline Bacillus sp. 553 & $92.0 \mathrm{abc}$ & $158.5 \mathrm{ab}$ & $12.0 \mathrm{~b}$ & $40.5 f$ \\
\hline Bacillus sp. 638 & $87.5 \mathrm{abcd}$ & $137.0 \mathrm{ab}$ & $8.3 \mathrm{~cd}$ & $46.5 \mathrm{cde}$ \\
\hline Bacillus sp. 933 & $97.0 \mathrm{ab}$ & $137.5 \mathrm{ab}$ & $1.5 \mathrm{gh}$ & $60.5 b$ \\
\hline Enterobacter sp. 632 & $81.8 \mathrm{bcde}$ & $70.0 \mathrm{cde}$ & $2.8 \mathrm{~g}$ & $60.0 \mathrm{~b}$ \\
\hline Pseudomonas sp. 677 & $71.2 \mathrm{e}$ & $31.5 \mathrm{e}$ & $3.0 \mathrm{~g}$ & $60.5 b$ \\
\hline Bacterial isolate 1 & $82.1 \mathrm{bcde}$ & $137.0 \mathrm{ab}$ & $8.3 \mathrm{~cd}$ & $45.5 \mathrm{def}$ \\
\hline Bacterial isolate 2 & $80.2 \mathrm{cde}$ & $111.0 \mathrm{bc}$ & $10.5 \mathrm{bc}$ & $40.0 \mathrm{f}$ \\
\hline Bacterial isolate 3 & $70.7 \mathrm{e}$ & $53.0 \mathrm{de}$ & $0 \mathrm{~h}$ & $90.0 \mathrm{a}$ \\
\hline Bacterial isolate 4 & $92.3 \mathrm{abc}$ & $147.0 \mathrm{ab}$ & $3.3 \mathrm{fg}$ & $52.0 \mathrm{c}$ \\
\hline
\end{tabular}

and moderately by Pestalotiopsis sp., Talaromyces sp. and Gliocladium roseum. Epicoccum sp. produced the largest inhibition zone (Table 3). Several other fungi sporulated profusely, including Aspergillus sp., Cladosporium sp. and Penicillium sp. They grew sporadically over the agar plate making assessment of $B$. cinerea growth difficult. Both Trichoderma sp. isolates also significantly inhibited growth of $B$. cinerea. While neither isolate produced an inhibition zone, each grew rapidly and markedly reduced mycelial growth (Table 3).

\section{Effect of potential antagonists on flower abscission}

Several bacterial (Bacillus sp. and Pseudomonas sp.), yeast (Aureobasidium spp.) and fungal (Epicoccum sp., Fusarium sp. and Trichoderma sp.) isolates were tested in vivo. These isolates had no significant effect on the number of days to flower abscission when inoculated alone (Table 4). Botrytis cinerea significantly reduced the number of days to flower abscission in all 3 experiments. Pseudomonas sp. 677 was the most antagonistic microorganism. This bacterium significantly delayed flower abscission by 3 days when co-inoculated with $B$. cinerea compared with inoculation with $B$. cinerea only. Likewise,
Trichoderma harzianum significantly delayed waxflower flower abscission. However, Aureobasidium sp. 274 and 468 had no effect of waxflower flower abscission (Table 4).

\section{Discussion}

The result achieved with Pseudomonas sp. 677 warrants its further investigation as a potential biological control agent for preharvest or postharvest application against B. cinerea on waxflower. Although Bacillus sp. 480 and isolates of Aureobasidium sp. also performed well in vitro, they did not significantly delay waxflower flower abscission. It was anticipated that yeast isolates might provide adequate control of $B$. cinerea on waxflower, since yeasts have been used with success against $B$. cinerea on other crops (Elad et al. 1994; Mercier and Wilson 1994). However, as was found by Janisiewicz (1987) during screening of microbial antagonists for the control of Penicillium expansum (blue mould) on apples, there were discrepancies between the in vitro and in vivo results.

As noted, the performance of microbial antagonists on plant organs in biocontrol assays does not necessarily mean that the same antagonists will perform well under field conditions (Tatagiba et al. 1998). The level of control 
Table 2. Relative ability of yeast isolates to inhibit Botrytis cinerea mycelial growth after incubation for 7 days at $25^{\circ} \mathrm{C}$ on half-strength potato dextrose agar

Means within each column followed by the same letter are not significantly different at $P=0.05$

Total number of observations for germination percentage was 10 ( 2 replications $\times 5$ samples) and germ tube length was 20 ( 2 replications $\times 10$ samples)

Aureobasidum spp., pink yeasts and white yeasts were obtained from Dr Marcelle Stirling, Biological Crop Protection; all other yeasts were isolated from waxflower.

Significance: inhibition zone, $P=0.009$; colony diameter, $P<0.001$

\begin{tabular}{lcc}
\hline Isolate & $\begin{array}{c}\text { Inhibition } \\
\text { zone }(\mathrm{mm})\end{array}$ & $\begin{array}{c}\text { Colony } \\
\text { diameter }(\mathrm{mm})\end{array}$ \\
\hline No. of replicates $(n)$ & 2 & 2 \\
Control & $0 \mathrm{~b}$ & $90.0 \mathrm{a}$ \\
Aureobasidium sp. 140 & $3.0 \mathrm{a}$ & $56.0 \mathrm{~b}$ \\
Aureobasidium sp. 274 & $1.8 \mathrm{a}$ & $56.0 \mathrm{~b}$ \\
Aureobasidium sp. 468 & $2.3 \mathrm{a}$ & $53.0 \mathrm{bc}$ \\
Pink yeast Q6 & $0 \mathrm{~b}$ & $90.0 \mathrm{a}$ \\
Pink yeast Q34 & $0 \mathrm{~b}$ & $90.0 \mathrm{a}$ \\
Pink yeast 373 & $2.3 \mathrm{a}$ & $49.5 \mathrm{c}$ \\
White yeast 268 & $0 \mathrm{~b}$ & $90.0 \mathrm{a}$ \\
White yeast 711 & $0 \mathrm{~b}$ & $90.0 \mathrm{a}$ \\
Yeast isolate 1 & $0 \mathrm{~b}$ & $90.0 \mathrm{a}$ \\
Yeast isolate 2 & $0 \mathrm{~b}$ & $90.0 \mathrm{a}$ \\
\hline
\end{tabular}

achieved by the antagonists in the biocontrol assays on waxflower might well have been enhanced by stable environmental conditions inside the jars used in these experiments. Constant temperature and high relative humidity should favour rapid germination and colonisation of the waxflowers by the antagonists. It is unlikely that environmental conditions would be so favourable during normal postharvest handling. Moreover, environmental conditions in the field are even less favourable. Leaf and flower surfaces can be hostile environments to microbial antagonists (Elad 1990). Fluctuating temperature and relative humidity, the absence of free water, and other variables, such as leaf exudates, wind and UV radiation, can all hamper colonisation by microorganisms (Elad 1990). Yeasts are believed to be relatively well adapted to cope with environmental fluctuations (Blakeman 1993). However, the isolates tested failed to control $B$. cinerea on waxflower, even under seemingly favourable conditions.

Sutton et al. (1997) suggest that the filamentous fungi Gliocladium roseum is an effective and versatile $B$. cinerea antagonist. The Gliocladium roseum isolate tested in these experiments displayed a degree of antagonism towards B. cinerea. However, this isolate was problematical, like the Talaromyces sp., Nigrospora sp. and Pestalotiopsis sp. isolates, because of poor sporulation. Therefore, the isolate of Epicoccum sp. that produced the largest inhibition zone in vitro was selected for further testing in vivo. Epicoccum
Table 3. Relative ability of fungal isolates to inhibit Botrytis cinerea mycelial growth after incubation for 7 days at $25^{\circ} \mathrm{C}$ on half-strength potato dextrose agar

Means within each column followed by the same letter are not significantly different at $P=0.05$

Total number of observations for germination percentage was 10 ( 2 replications $\times 5$ samples) and germ tube length was 20 ( 2 replications $\times 10$ samples)

All fungal isolates were obtained from waxflower, with the exception of Talaromyces sp., which was obtained from Dr Lindy Coates, DPI, and Trichoderma harzianum, which was obtained from Dr Andrew Rath, Abbott Laboratories

Gliocladium roseum was not included in conidial germination and germ tube elongation experiments due to poor sporulation in culture Significance: inhibition zone, $P<0.001$; colony diameter, $P<0.001$

\begin{tabular}{lcc}
\hline Isolate & $\begin{array}{c}\text { Inhibition } \\
\text { zone }(\mathrm{mm})\end{array}$ & $\begin{array}{c}\text { Colony } \\
\text { diameter }(\mathrm{mm})\end{array}$ \\
\hline No. of replicates $(n)$ & 2 & 2 \\
Control & $0 \mathrm{e}$ & $90.0 \mathrm{a}$ \\
Alternaria $\mathrm{sp}$. & $0.8 \mathrm{~d}$ & $47.0 \mathrm{c}$ \\
Aspergillus $\mathrm{sp}$. & $0 \mathrm{e}$ & $15.5 \mathrm{f}$ \\
Cladosporium sp. & $0 \mathrm{e}$ & $55.0 \mathrm{~b}$ \\
Epicoccum sp. & $5.0 \mathrm{a}$ & $50.0 \mathrm{bc}$ \\
Fusarium sp. & $2.3 \mathrm{c}$ & $33.0 \mathrm{~d}$ \\
Gliocladium roseum & $0.0 \mathrm{e}$ & $48.5 \mathrm{c}$ \\
Nigrospora sp. & $1.0 \mathrm{~d}$ & $33.5 \mathrm{~d}$ \\
Penicillium sp. & $0 \mathrm{e}$ & $26.0 \mathrm{e}$ \\
Pestalotiopsis sp. & $0 \mathrm{e}$ & $45.0 \mathrm{c}$ \\
Phoma sp. & $0 \mathrm{e}$ & $50.0 \mathrm{bc}$ \\
Talaromyces sp. & $3.3 \mathrm{~b}$ & $44.5 \mathrm{c}$ \\
Trichoderma sp. & $0 \mathrm{e}$ & $23.0 \mathrm{e}$ \\
Trichoderma harzianum & $0 \mathrm{e}$ & $33.5 \mathrm{~d}$ \\
\hline
\end{tabular}

purpurascens was found to prevent grey mould disease, notably lesion formation on bean leaves and petals, under a range of environmental conditions (Hannusch and Boland 1996). However, not all Epicoccum species are saprophytic. Some are characterised as being opportunistic plant pathogens (Bruton et al. 1993). For example, Epicoccum nigrum has been reported to infect melon fruit and cause red discolouration of the skin (Bruton et al. 1993). The fungus was also found to be pathogenic towards cucumber, tomato, apple and pear (Bruton et al. 1993). Further pathogenicity testing of the isolate obtained from waxflower flowers would be necessary to ensure it is saprophytic. High concentrations of Epicoccum sp. conidia may also have harmful effects on plant growth. It is believed that the dark coloured conidia can interfere with light reception (Zhou and Reeleder 1991).

As expected, Trichoderma harzianum was the most antagonistic fungus in vivo against $B$. cinerea. A commercial formulation of T. harzianum (Trichodex) is available and has been used for the control of B. cinerea on other crops, including grapes and strawberries (Elad 1994; Kovach 1996; Burgess and Keane 1997). However, Trichoderma spp. have been reported to be ineffective biocontrol agents in dry 
Table 4. Relative ability of two bacterial isolates, two yeast isolates and three fungal isolates to inhibit waxflower cv. 'CWA Pink' flower abscission from petioles when they were incubated at $20^{\circ} \mathrm{C}$ and $>95 \%$ relative humidity

Row and column means for bacterial, yeast and fungal isolates followed by the same letter are not significantly different at $P=0.05$

\begin{tabular}{|c|c|c|c|}
\hline \multirow[t]{2}{*}{ Isolate } & \multicolumn{2}{|c|}{ Days to flower abscission } & \multirow{2}{*}{$\begin{array}{l}\text { Row means } \\
\quad(n=20)\end{array}$} \\
\hline & Control & Inoculated & \\
\hline No. of replicates $(n)$ & 10 & 10 & \\
\hline \multicolumn{4}{|l|}{ Bacterial isolates $^{\mathrm{A}}$} \\
\hline Control & 12.8 & 6.1 & $9.5 b$ \\
\hline Bacillus sp. 480 & 13.4 & 8.1 & $10.8 \mathrm{ab}$ \\
\hline Pseudomonas sp. 677 & 14.7 & 10.7 & $12.7 \mathrm{a}$ \\
\hline Column means $(n=30)$ & $13.6 \mathrm{a}$ & $8.3 b$ & \\
\hline \multicolumn{4}{|l|}{ Yeast isolates $^{\mathrm{B}}$} \\
\hline Control & 13.8 & 7.5 & $10.7 \mathrm{a}$ \\
\hline Aureobasidium sp. 274 & 15.0 & 8.6 & $11.8 \mathrm{a}$ \\
\hline Aureobasidium sp. 468 & 14.0 & 9.8 & $11.9 \mathrm{a}$ \\
\hline Column means $(n=30)$ & $14.3 \mathrm{a}$ & $8.6 b$ & \\
\hline \multicolumn{4}{|l|}{ Fungal isolates ${ }^{C}$} \\
\hline Control & 13.0 & 5.9 & $9.5 b$ \\
\hline Epicoccum sp. & 12.9 & 9.3 & $11.1 \mathrm{ab}$ \\
\hline Fusarium sp. & 12.0 & 7.2 & $9.6 \mathrm{~b}$ \\
\hline Trichoderma harzianum & 13.2 & 13.2 & $13.2 \mathrm{a}$ \\
\hline Column means $(n=40)$ & $12.8 \mathrm{a}$ & $8.9 b$ & \\
\hline
\end{tabular}

A Significance: isolate, $P=0.006$; inoculation, $P<0.001$; isolate $\times$ inoculation, n.s.

${ }^{\mathrm{B}}$ Significance: isolate, n.s.; inoculation, $P<0.001$; isolate $\times$ inoculation, n.s.

CSignificance: isolate, $P=0.005$; inoculation, $P<0.001$; isolate $\times$ inoculation, $P=0.023$.

conditions (Köhl et al. 1995). Because of these characteristics, the search for more durable antagonists microbes is ongoing.

Unsightly mycelium associated with surface colonisation by fungal isolates can be a problem with using filamentous fungi as microbial antagonists. Thus, most fungal antagonists may be impractical as postharvest biological control agents for $B$. cinerea on waxflower flowers. In contrast, such fungal antagonists may be beneficial if employed for competitive exclusion of $B$. cinerea in the field before harvest. Preharvest conditions should not be conducive to proliferation. In this context, future research could determine if the more promising fungal antagonists, such as Trichoderma harzianum and Gliocladium roseum can reduce preharvest colonisation of waxflower by B. cinerea.

In conclusion, future developments in biological control of $B$. cinerea on waxflower might entail an integrated preand postharvest biological control approach. Saprophytic fungal antagonists could be used in the field to colonise necrotic material and reduce $B$. cinerea sporulation. Fungi, such as Trichoderma spp., could also be used to destroy survival structures like sclerotia (Elmer and Köhl 1998). Antagonistic yeasts and bacteria, such as Pseudomonas 677, might then be employed after harvest to colonise flowers. Their direct competition with $B$. cinerea should prevent infection of healthy tissues (Elmer and Köhl 1998).

\section{Acknowledgments}

Financial support for this research was provided, in part, by an Australian Postgraduate Award and the Rural Industries Research and Development Corporation. The authors gratefully acknowledge the donation of bacterial, yeast and fungal isolates by Dr John Alcorn, Dr Andrew Rath and Dr Marcelle Stirling.

\section{References}

Barnett HL (1960) 'Illustrated genera of imperfect fungi.' (Burgess Publishing Company: Minneapolis, USA)

Blakeman JP (1993) Pathogens in the foliar environment. Plant Pathology 42, 479-493.

Blakeman JP, Atkinson P (1981) Antimicrobial substances associated with the aerial surfaces of plants. In 'Microbial ecology of the phylloplane'. (Ed. JP Blakeman) pp. 245-265. (Academic Press: London)

Brodie IDS, Blakeman JP (1975) Competition for carbon compounds by a leaf surface bacterium and conidia of Botrytis cinerea. Physiological Plant Pathology 6, 125-135.

Bruton BD, Redlin SC, Collins JK, Sams CE (1993) Postharvest decay of cantaloupe caused by Epicoccum nigrum. Plant Disease 77, 1060-1062.

Burgess DR, Keane PJ (1997) Biological control of Botrytis cinerea on chickpea seed with Trichoderma spp. and Gliocladium roseum: indigenous versus non-indigenous isolates. Plant Pathology 46, 910-918.

Elad Y (1990) Reasons for the delay in development of biological control of foliar pathogens. Phytoparasitica 18, 99-105.

Elad Y (1994) Biological control of grape grey mould by Trichoderma harzianum. Crop Protection 13, 35-38.

Elad Y, Kohl J, Fokkema NJ (1994) Control of infection and sporulation of Botrytis cinerea on bean and tomato by saprophytic yeasts. Phytopathology 84, 1193-1200.

El Ghaouth A, Arul J, Grenier J, Asselin A (1992) Antifungal activity of two postharvest pathogens of strawberry fruits. Phytopathology $\mathbf{8 2}$, 398-402.

Elmer PAG, Köhl J (1998) The survival and saprophytic competitive ability of the Botrytis spp. antagonist Ulocladium atrum in lily canopies. European Journal of Plant Pathology 104, 435-447.

Hannusch DJ, Boland GJ (1996) Interactions of air temperature, relative humidity and biological control agents on grey mould of bean. European Journal of Plant Pathology 102, 133-142.

Janisiewicz WJ (1987) Postharvest biological control of blue mold on apples. Phytopathology 77, 481-485.

Janisiewicz WJ, Roitman J (1988) Biological control of blue mold and gray mold on apple and pear with Pseudomonas cepacia. Phytopathology 78, 1697-1700.

Joyce DC (1988) Postharvest characteristics of Geraldton wax flowers. Journal of the American Society for Horticultural Science 13, $738-742$.

Joyce DC (1993) Postharvest floral organ fall in Geraldton waxflower (Chamelaucium uncinatum Schauer). Australian Journal of Experimental Agriculture 33, 481-487.

Joyce D, Wearing A (1996) Fungicides fight flower drop. Australian Horticulture 94, 58-59. 
Köhl J, Gerlagh M, De Haas BH, Krijger MC (1998) Biological control of Botrytis cinerea in cyclamen with Ulocladium atrum and Gliocladium roseum under commercial growing conditions. Phytopathology 88, 568-575.

Köhl J, Molhoek WML, van der Plas CH, Fokkema NJ (1995) Effect of Ulocladium atrum and other antagonists on sporulation of Botrytis cinerea on dead lily leaves exposed to field conditions. Phytopathology 85, 393-401.

Kovach J (1996) Using bees to deliver a biological control agent to control gray mould of strawberries. Strawberry IPM Update 3, 3-5.

Mercier J, Wilson CL (1994) Colonization of apple wounds by naturally occurring microflora and introduced Candida oleophila and their effect on infection by Botrytis cinerea during storage. Biological Control 4, 138-144.

Olley CM, Joyce DC, Irving DE (1996) Changes in sugar, protein, respiration, and ethylene in developing and harvest Geraldton waxflower (Chamelaucium uncinatum) flowers. New Zealand Journal of Crop and Horticultural Science 24, 143-150.

Prusky D, Keen NT (1993) Involvement of preformed antifungal compounds in the resistance of subtropical fruits to fungal decay. Plant Disease 77, 114-119.

Seaton KA, Woods WM, Walsh PG (1993) Postharvest disinfestation of arthropods from field-grown Geraldton wax (Chamelaucium uncinatum Schauer). New Zealand Journal of Crop and Horticultural Science 21, 147-151.

Stirling, AM (1995). 'The role of epiphytic microorganisms in the suppression of Colletotrichum gloeosporioides on avocado.' $\mathrm{PhD}$ Thesis, The University of Queensland.
Sutton JC (1995) Evaluation of micro-organisms for biocontrol: Botrytis cinerea and strawberry, a case study. Advances in Plant Pathology 11, 173-190.

Sutton JC, Li DW, Peng G, Yu H, Zhang P, Valdebenito-Sanhueza RM (1997) Gliocladium roseum: a versatile adversary of Botrytis cinerea in crops. Plant Disease 81, 316-328.

Tatagiba J da S, Maffia LA, Barreto RW, Alfenas AC, Sutton JC (1998) Biological control of Botrytis cinerea in residues and flowers of rose (Rosa hybrida). Phytoparasitica 26, 8-19.

Taylor M, Joyce D, Wearing A, Simons D (1996) Control of postharvest pathogens of waxflower (Chamelaucium uncinatum). In 'Fourth national workshop for Australian native flowers'. The University of Western Australia, Perth, 28-30 September 1996. pp. 146-153. (The University of Western Australia: Perth)

Tomas A, Wearing AH, Joyce DC (1995) Botrytis cinerea: a causal agent of premature flower drop in packaged Geraldton waxflower. Australasian Plant Pathology 24, 26-28.

Zhou T, Reeleder RD (1991) Colonization of bean flowers by Epicoccum purpurascens. Phytopathology 81, 774-778.

Received 6 August 2000, accepted 16 February 2001 